\title{
Research on Application of Construction Technology of Energy Saving Fuyong Huang ${ }^{1}$ \\ ${ }^{1}$ Liaoning Jianzhu Vocational University, Liaoyang, Liaoning, 111000 73691468@163.com
}

\author{
Keywords: Energy Saving Technology; Construction Industry; Developing Progess
}

\begin{abstract}
At this stage, the social and economic progress leads the building industry into a new period of development of civilization. Indicators of buildings is an important aspect to measure the building urban development, for people's production and life has a very important role, it will also affect the environment of a region optimization, cultural development and technological progress. However, in the society the energy loss, the energy consumption of buildings is very great, which makes the development of the construction industry much difficult. Therefore, energy-saving construction industry has become an important task of the current social and economic development and has a very important significance to promote social and economic development, improve the living environment. In addition, the introduction of relevant policies and implementation of a various energy-saving awareness also make the construction industry to promote the implementation of this project.
\end{abstract}

\section{Introduction}

Architecture is essentially energy-efficient buildings, its meaning is in the whole life cycle of the building, the most efficient use and conservation of resources through energy and water conservation, energy saving, rational design and materials, land and other aspects and embodiments, both to conserve resources while protecting the environment, scientific and rational use of space at the same time, and nature in harmony. The so-called "green building" and "green" does not mean the traditional sense of three-dimensional green, green roofs, green atrium, but represents a kind of architectural design, but to build environment-friendly construction, full use of natural environmental resources, and the natural and social environment of harmony and unity, resource utilization to achieve dynamic equilibrium, so green building is also known as energy saving construction, ecological construction, building and sustainable development.

Energy storage is a top priority affect people's livelihood. China's energy consumption in buildings has accounted for nearly $28 \%$ of total energy consumption society, and the annual growth rate of more than $1 \%$ of rapid growth, Click here to estimate, to 2020, the building energy consumption will occupy estimate of China's energy consumption $40 \%$. Chinese Academy of Sciences survey shows that China is one of the world's most serious waste of natural resources countries, ranked 56 in the 59 countries surveyed. According to statistics, China's energy efficiency is only the United States 26.9\%, Japan 11.5\%. In the "Eleventh Five-Year Plan", Chinese government has made energy efficiency as a top priority. In 2008 the Chinese government launched the 10 key energy conservation projects, estimated to save 220 million tons of energy. EEB accounted for 100 million tons, accounting for about 45\%. Data show that the building energy consumption accounts for half of domestic energy-saving projects. Therefore, to promote energy conservation, described as imminent. Energy-saving technology is an important support building energy efficiency is an important means of achieving 2020 emission reduction targets, building energy efficiency is one of the energy-saving projects, with real urgency and strategic importance, its value far unable to use the economy to measure. Leaving the energy-saving technology talk EEB is unrealistic. In the next 15 years, China is committed to China from the current inefficient energy users become efficient energy user. To improve the situation of energy consumption, but also need to further improve the energy-saving technologies, from Electrical Equipment to industries of coal, oil, construction and other joint unremitting efforts. 


\section{Basic Theory of Energy Saving Technologies in Building Construction}

Green building is essentially energy-efficient buildings, its meaning is in the whole life cycle of the building, the most efficient use and conservation of resources through energy and water conservation, energy saving, rational design and materials, land and other aspects and implementation, both to conserve resources while protecting the environment, scientific and rational use of space at the same time, and nature in harmony. The so-called "green building" and "green" does not mean the traditional sense of three-dimensional green, green roofs, green atrium, but represents a kind of architectural design, but to build environment-friendly construction, full use of natural environmental resources, and the natural and social environment of harmony and unity, resource utilization to achieve dynamic equilibrium, so green building is also known as energy saving construction, ecological construction, building and sustainable development.

From the late 1970s until today, with the worsening environmental pollution, energy crisis, land degradation, ecological imbalance and other issues, the relationship between architecture and the environment around the world more and more concern and attention. Nearly 10 years, the design and construction of green buildings construction industry has become an international issue of common concern. Rio de Janeiro, Brazil in 1992, "the United Nations Environment and Development Conference", it was the first time explicitly put forward the "green building" concept, green building thus becoming a research system both comfortable and healthy and environmental protection, and more many countries and regions attention and promotion, has become one of the important directions within the current world architectural development.

\section{Application of Energy Saving Technology in the Construction Industry}

External Structure System. Improving indoor comfort, improve the living environment to start, the building energy efficiency as an integrated system designed to reduce building energy consumption. Building energy efficiency design must be a comprehensive system design, rather than using a single technology, nor at the expense of the cost of indoor comfort; on the contrary, starting from improving indoor comfort, learn advanced and mature technology, with China's national conditions combination of building a series of optimized design, they will naturally achieve efficient building energy efficiency, rather than passively follow the design of energy conservation, the use of extensive energy use patterns, otherwise, building energy efficiency will always be a slogan. The main use of the following measures: polystyrene board $(100 \mathrm{~mm})$, A-class fire rock wool insulation $(135 \mathrm{~mm})$ exterior insulation and roof insulation $(200 \mathrm{~mm})$; chrysanthemum hanging stone Xinjiang fine air insulation layer; Low-E double thermal insulating glass broken window; aluminum shutter-type external shading, reducing summer cooling energy consumption, flexible control room light environment.

EIFS can be compared to building a layer of warm coat to wear. In summer, reduce direct solar radiation surface of the room, to minimize heat transfer inside and outside the room. And you need to do indoors to keep warm in winter, the need to reduce indoor heat loss through the use of more mature exterior paste extruded polystyrene board, breathing walls and hanging stone wool insulation technology. Building envelope can greatly reduce the heat transfer coefficient, but also increases the thermal resistance of the building envelope.

In the construction of the roof and parapet portion is provided insulation layer can effectively block the solar radiation at the top of the house. And the insulation layer extends to the surface permafrost below the roof or on the ground in the garage at an additional polystyrene plates can be effectively isolated from the ground floor and basement of the energy transfer, the roof, and the exterior surface of the insulation layer of insulation to form a closed system insulation system, improve the insulation performance of the building as a whole, full barrier energy loss.

Roof insulation and waterproof roof insulation and waterproof performance directly affect the top household indoor comfort and energy consumption. The total heat transfer coefficient should be less than or equal to roofing $0.33 \mathrm{~W} /\left(\mathrm{m}^{2} . \mathrm{K}\right)$ frozen ground insulation line Beijing is 0.8 meters, the land will be the frozen water, but will not be less than 0.8 meters after the frozen projects insulation 
in the building process of the first floor of the floor, which was designed with the garage roof, making the insulation performance of the building is more superior.

\section{Temperature and Humidity Constant Oxygen System}

To break the traditional way of cooling and heating, hot and cold items in radiant tubes embedded in the concrete floor or the capillary network laying in roof, ceiling following summer pass into the cold water in the pipe $18-21{ }^{\circ} \mathrm{C}$, the winter passed through 28 to $31{ }^{\circ} \mathrm{C}$ hot water, and the indoor temperature adjustment control $20-26{ }^{\circ} \mathrm{C}$ to radiation in the form of the heat spread to every corner of the room. The radiation system at the same time improves people's living comfort, significantly reducing power consumption of conventional air conditioning system. Through intelligent control system to synchronize the system, it can make power the air conditioning system with adjustable temperature. The system uses low-temperature and high-temperature hot water and cold water for air-conditioning heat source in line with the principle of energy conservation, air conditioner efficiency than conventional air conditioner efficiency can be increased by more than $30 \%$.

At present, the system can be divided into three types of radiation in the form in which the capillary network system is the use of $4.3 \times 0.8 \mathrm{~mm}$ of PPR plastic capillary composition grid, grid spacing of $10 \mathrm{~mm}-30 \mathrm{~mm}$, the capillary network system is mainly played with the collection, distribution, transportation functional liquid, like the body and blood capillaries. In the liquid flow rate grid between $0.05-0.2 \mathrm{~m} / \mathrm{s}$, and human capillary blood flow is substantially the same. Winter low temperature hot water through capillary network, gentle radiant heat to the room. Summer high temperature is injected into the capillary network of cold water, soft radiation cooling capacity to the room. Since the appearance of the capillary network area, the heat transfer area is large, heat transfer speed faster than traditional methods, therefore a higher heat transfer efficiency.

\section{New Energy Systems}

Ground source heat pump system is a new environmentally friendly utilization of shallow geothermal energy utilization system capable of heating and cooling. In winter, the heat transfer through ground heat from the soil into the underground building, summer heat is then transferred to the underground chamber to the soil, while the cold underground transferred to the building, forming a thermal cycling system, ensure that the temperature in the room demand. Due to the shallow surface temperature is relatively stable throughout the year, soil and air temperature difference is usually 17 degrees higher than the ambient air temperature in winter, lower in summer than the ambient air temperature, is a good source heat pump and air conditioning cold source, such temperature characteristics It makes ground source heat pump efficiency than conventional air conditioning systems is higher by $40 \%$ to $60 \%$, so you can save up to $50 \%$ of operating costs, so we will call it energy-efficient air conditioning system. Ground source heat pump and air source heat pump pollutant emissions can be reduced compared to more than $40 \%$, compared with more than 70 percent reduction in electric heating, the true realization of energy conservation. And ground-source heat pump system also has a multi-purpose, low maintenance costs, long life and other characteristics.

Use of solar energy in the building there are many ways, such as solar water heaters, solar photovoltaic power generation and direct use (light guide tube lighting) system. Wherein the light pipe lighting system as a clean and efficient energy-saving technology, has been widely recognized and applied. Lighting light pipe system via the outdoor lighting apparatus to capture and collect sunlight, and introduced into the light guide tube for transmission, and finally by the indoor ceiling mounted diffuser at the light uniformly irradiated to the interior, the system can be reduced inside the building during the day more than 80 percent of lighting energy consumption and more than 10 percent of air conditioning and refrigeration energy consumption.

Solar photovoltaic solar panels that require relatively large area, often the other projects are the solar panels installed on the roof of the building, but the roof of the present project design for 
sloping roof, increasing the difficulty and cost of installation of solar panels, all not recommended for use in high-rise building projects. However, to achieve green building energy efficiency purposes, need to begin to reduce the scope of application of solar photovoltaic, for example son said, like residential street and garden lights with this technology, so rely on photovoltaic panels during the day to absorb and store energy for lighting at night. The system has reliable performance, high luminous efficiency, easy installation, no laying of cables and wires, no AC power electricity, photosensitive control, and long life and other advantages.

\section{Utilization of Water Resources}

For rainwater resources, since Beijing annual rainfall is small, less than $800 \mathrm{~mm}$, therefore, from Beijing geography and climate, etc. These actual situations have taken into account technical and economic the project uses natural rainwater penetration and use of collection strategies. Project uses highly efficient water-saving appliances, building indoor use of water-saving toilets and faucets; large green venue design, combined with the landscape design will collect rainwater and discharge to the green landscape pool or local infiltration. Roofing and road rainwater have been flowing into the municipal storm sewer pipes. In order to better achieve the effect of water seepage, water seepage its pavement materials; to reduce runoff and increase affore station area, there are more than twenty thousand square meters. And on the ground under green landscape designed area of one thousand square meters of the reservoir, designed to store rainwater, rainwater can be used to water the flowers, water gardens and so on.

\section{Conclusion}

Sustainable development is not a new topic now, but its implementation has suffered a variety of obstacles, economic development, science and technology to improve and accelerate the urbanization process, and vigorously develop and use a variety of resources, are to expense of the environment. Social development is based on economic development, if the economy can not be sustained and healthy development, there is no basis for survival and sustained social and economic development. As an industry, real estate has comes to economic, social and environmental development of the three main body. Therefore, the development trend of this century estate is clearly necessary to use green energy, but also to meet the increasing needs. Green real estate concept is presented in this trend and become a goal of real estate. Therefore, environmental protection, energy conservation is the basic task of green real estate projects across the board. In practice, only green real estate takes into account the various requirements of the social benefits, economic benefits and meets the various industries involved and consumers, can it make truly develop.

\section{Acknowledgements}

Project Name: construction engineering management professional production and teaching combined with the training mode of talents

Project level: Liaoning Province Vocational Technical Education Institute of scientific research planning project

Project number: LZY15561

\section{References}

[1] Gu Xuewen. Premises Market-Oriented Economy and Green Energy Efficient Building. Building Economy, 2006,10: 42-45.

[2] Gu Weihong. Explore the Western Region to Promote Green Energy-Saving Building Services Circular Economy. Value Engineering, 2006, 12: 12-14. 
[3] Chang Zhen. The Relationship Green Building Design and Construction of Green Energy. Sichuan Building, 2006,06: 63-65.

[4] Wang Sound. Thinking about Promoting Green Energy Efficient Building Market-Oriented. Construction, 2007,01: 58-60.

[5] Wang Jie. Green Building Design and Green Energy Efficient Building. Building Materials and Decoration, 2008,04: 266-267. 